\title{
Effect of Square Defect on 2.4GHz Microstrip Antenna
}

\author{
Vidyadhar S Melkeri ${ }^{1}$, P V Hunagund ${ }^{2}$, Lakshmi G K ${ }^{3}$ \\ ${ }^{1}$ Research scholar Department of Applied Electronics, Gulbarga University, Kalaburagi \\ ${ }^{2}$ Department of Applied Electronics Gulbarga University Kalaburagi \\ ${ }^{3}$ Sri Krishna Institute of Technology, Bangalore
}

\begin{abstract}
Better performance is always being a challenge for microwave engineers. To overcome some of the disadvantages of the Microstripantennamany approaches have been made, to achieve the better performances and bandwidth, from the review of literature it is found that there is a tremendous developments in the fields of Defected Ground Structure (DGS), on printed Microstrip antennas is been made, with a particular geometry and shape which is etched out as a single defect or periodic configuration to create a feature of stopping wave propagation through the substrate over a frequency range. In this paper an approach to improve the performance and bandwidth of square Microstrip antenna of frequency $2.4 \mathrm{GHz}$ is made by embedding the patch antenna with a square ring defect in the ground plane. The simulation process has been done through Finite Element Machine (FEM) based software High Frequency Structure Simulator (HFSS) software. The properties of the antenna designed for $2.4 G \mathrm{~Hz}$ lead to antenna size miniaturization and better reflection coefficient with larger bandwidth and dual band operation. It is found that the antenna resonates at $1.6 G H z$ with the band width of $1100 \mathrm{MHz}$ and the overall size reduction is found to be $48 \%$ in comparison with the conventional square antenna, and also its found that the because of the defected structure etched out of the ground plane the copper usage is reduced to 30\%. Further it's also observed that proposed antenna finds its most of application in the lower band like IEEE 802.11 and ISM Bands.
\end{abstract}

Keywords: Antenna, Square defect, DGS, Bandwidth, HFSS.

\section{Introduction}

Microstrip antenna (MSA) technology has developed rapidly due to its numerous application and unique features in the field of microwave engineering, MSA has numerous advantages such as low volume, lesser cost, most importantly compatible with integrated circuits, which extends its application, In 1970's the first practical antenna [1] was designed. Since then, extensive research and development work in this field is taking place. Microstrip antennas also have their disadvantage which hinders the performance of the antenna, many research has been carried out to improve and overcome the disadvantages of the MSA.

Towards the achievement of the high data-rate and low signal power the microwave engineering is been focusing on the development to overcome the disadvantages, from the recent literature survey there is been a tremendous development in improving the performance using Defected Ground Structures (DGS), which is also known as Electronic Band Gap [1]. As the name suggest it's the intentionally created defect on the ground plane of the MSA under the printed transmission line and it perturbs the electromagnetic fields around the defect. Trapped electric fields give rise to the capacitive effect $(\mathrm{C})$, while the surface currents around a defect cause an inductive effect (L). This, in turn, results in resonant characteristics of a DGS They have different shapes and size with different frequency responses and equivalent circuit parameters.

The DGS underneath the transmission line disturbs the current distribution in the ground plane and modifies the equivalent line parameter over the defected region. Which indirectly influence the wave characteristics and exhibits band gap properties as present in EBG structures and also produce a slow wave effect, which helps in compacting of printed antenna.

\section{Design of DGS}

With a proper modeling technique we can obtain a basic mathematical model of the frequency based defect. A defect changes the current distribution in the ground plane of microstrip line, giving rise to equivalent inductance and capacitance. Thus DGS behaves like L-C resonator circuit coupled to microstrip line. When an RF signal is transmitted through a DGS-integrated microstrip line, strong coupling occurs between the line and the DGS around the frequency where DGS resonates. If the transmitted signal covers the resonant frequency of DGS, and most of the signal is stored in its equivalent parallel LC resonator. Basically modeling is classified into three main categories: (a) transmission line modeling [2]; (b) LC and RLC circuit modeling [3-4]; and (c) quasi-static modeling [5].

\section{Design of Proposed Antenna}

The proposed antenna is designed using the conventional design equations [6] and the conventional square antenna of frequency $2.4 \mathrm{GHz}$ was designed. Design consideration for required frequency i.e. $2.4 \mathrm{GHz}$ as given

Length L, usually

Patch thickness

Height of substrate h, usually

The dielectric constant is considered

Based on the above design considerations and equation the square MSA was designed with thickness of substrate as $0.016 \mathrm{~cm}$ and its relative permittivity from the calculation the length (L) and width (W) of patch is given as $3.01 \mathrm{~cm}$, and

\section{Volume 4 Issue 11, November 2015}




\section{International Journal of Science and Research (IJSR) \\ ISSN (Online): 2319-7064 \\ Index Copernicus Value (2013): 6.14 | Impact Factor (2014): 5.611}

the length and width of substrate is calculated using $6 \mathrm{~h}+\mathrm{L}$, $6 \mathrm{~h}+\mathrm{W}$, respectively. For the proposed antenna Microstrip line strip feed method was used to feed the signal. The top view of the conventional square MSA is as shown in Figure 1.

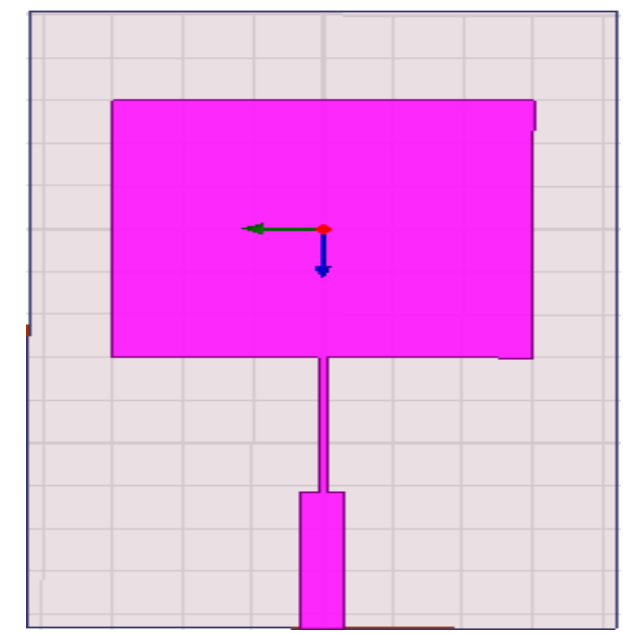

Figure 1: Top view of Square MSA

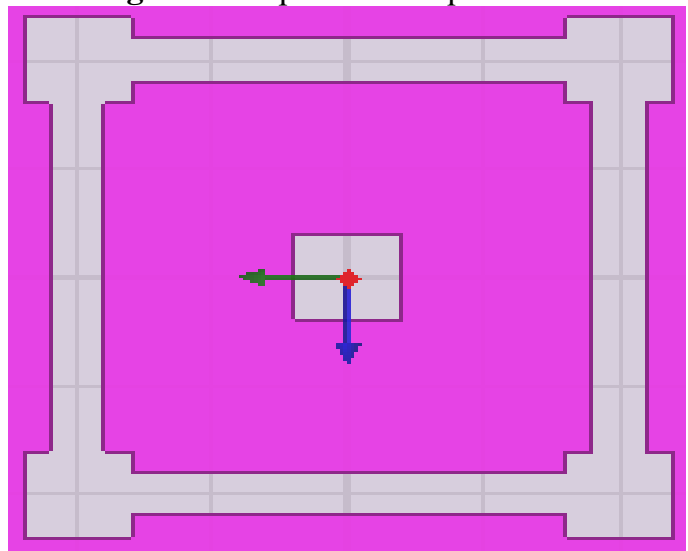

Figure 2: Structure of DGS.

Simulated and desired results of conventional MSA were obtained as designed for the frequency. In order to improve the performance and to obtain improvement of bandwidth and other parameters of the antenna the DGS of following structure was introduced. Figure 2 shows the shape and the dimension of the defect structure. This is calculated using transmission line model. The designed structure is then embedded with the conventional square patch antenna on the ground plane, i.e. it's etched out from the ground plane. Figure 3 shows the bottom view of the square MSA after embedding the antenna with DGS.

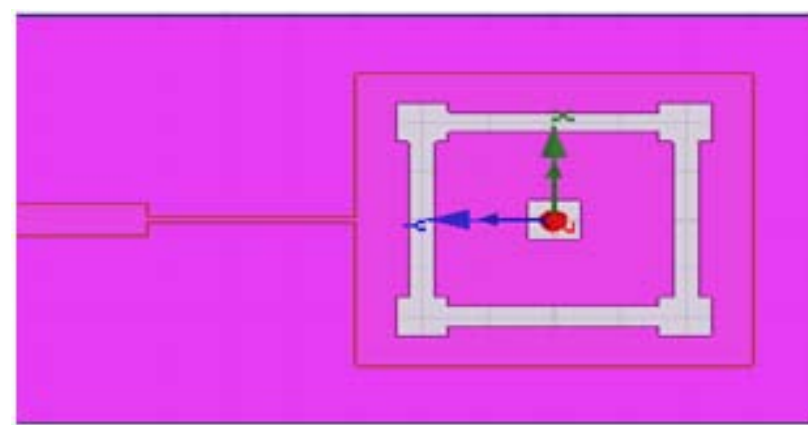

Figure 3: Bottom view of Square MSA with DGS

\section{Results and Discussion}

The Square ring shaped DGS as shown in the Figure 2 is been embedded with square MSA. The S11 parameter for the proposed antenna is calculated and the reflection coefficient of the antenna is obtained as shown in Figure 4. From the figure we can say that antenna is resonating with larger reflection coefficient of $-22.104 \mathrm{db}$ at $1.6825 \mathrm{GHz}$ with impedance bandwidth of $1100 \mathrm{MHz}$ which is much larger than that obtained for conventional square MSA. The bandwidth of designed antenna in percentage is $6.58 \%$.

Other parameters such as the overall size reduction of the designed antenna with respect to conventional square MSA is up to $42.8 \%$. Also it is observed that the antenna resonates both in lower as well as in higher band of frequencies that is at $1.68 \mathrm{GHz}$ and $3.22 \mathrm{GHz}$. Which gives the proposed antenna has dual band of operation and large bandwidth.

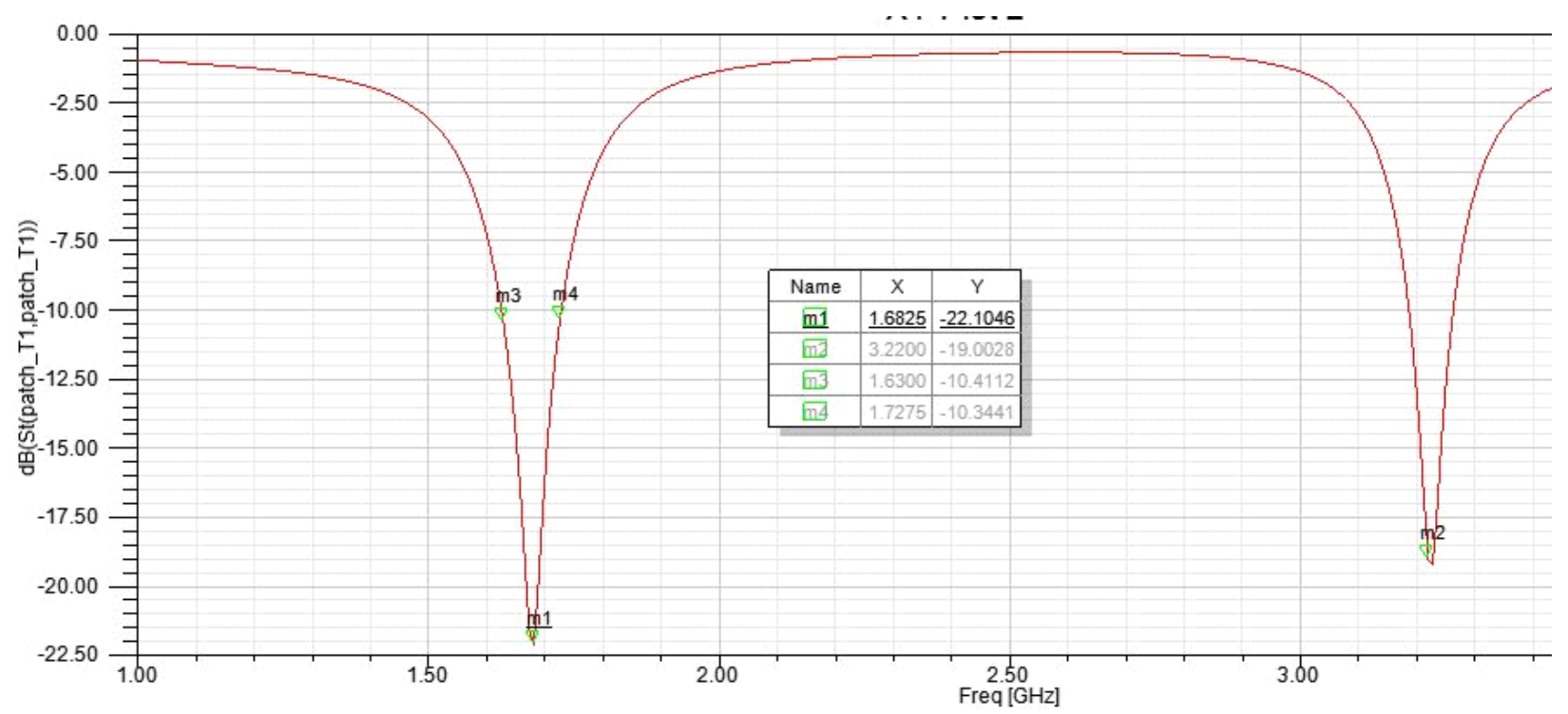

Figure 4: Reflection coefficient of designed antenna 


\section{International Journal of Science and Research (IJSR) \\ ISSN (Online): 2319-7064}

Index Copernicus Value (2013): 6.14 | Impact Factor (2014): 5.611

The radiation pattern of the proposed antenna is shown in Figure 5 from the figure it's observed the antenna radiation is Omni directional in azimuth plane, at resonant frequency of $1.68 \mathrm{GHz}$.

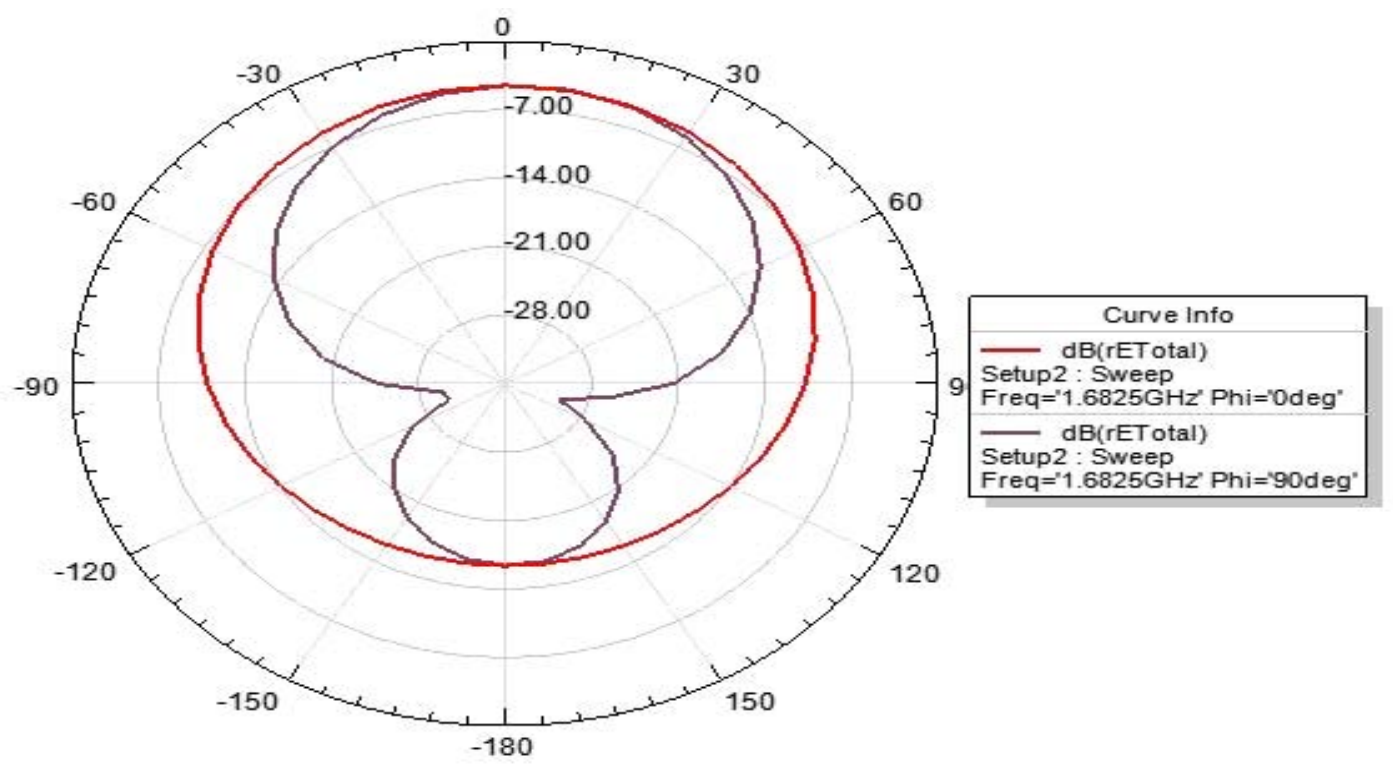

Figure 5: The Radiation pattern of the designed antenna

The gain of the antenna stands to be the most important factor among the parameters of the antenna; it is the ratio of radiated field intensity by test antenna to the radiated field intensity by reference antenna [7]. The gain of the antenna improves with DGS which is found to be $20.8 \mathrm{~dB}$ when compared with conventional square MSA (4.62dB).

From the smith chart Figure 6 given below can observe that the impedance match of the designed antenna is good.

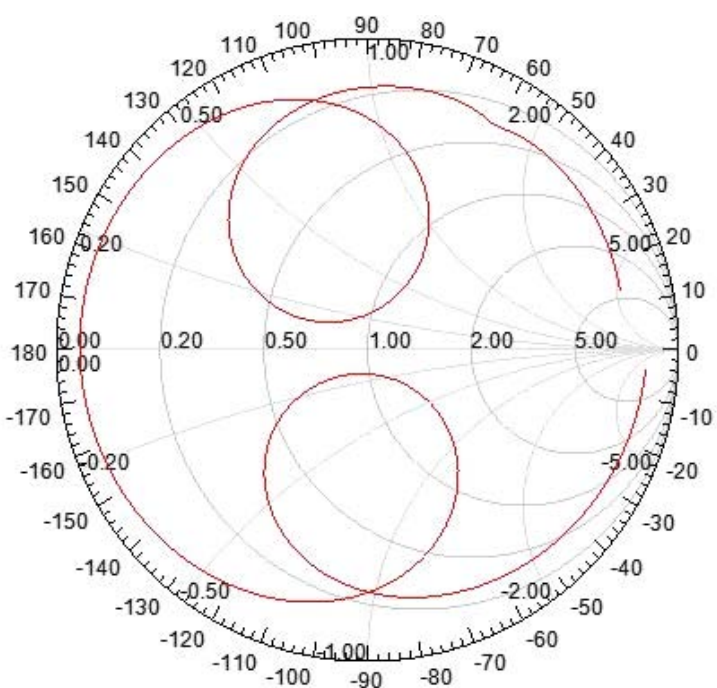

Figure 6: Smith chart of proposed antenna

The important point to be observed in the following results and simulation is that the proposed antenna is resonating for the dual band operation in the lower frequency as well as in the higher frequency due to which the bandwidth improvement also can be claimed in the proposed antenna.

\section{Conclusion}

From the detailed study it is observed that the conventional antenna designed for $2.4 \mathrm{GHz}$ when embedded with the square ring shape defected ground structure exactly below the patch, because of which the antenna resonates both in lower band as well as in the higher band giving dual band operation of the antenna. From which size reduction of $42.8 \%$ as well as the bandwidth of $1100 \mathrm{MHz}$ is obtained. When a conventional antenna is embedded with DGS not only the parameters of the antenna is improved as well as without changing the shape of the antenna we are reducing the amount of copper used in the design of the antenna. In this proposed antenna approximately $30 \%$ copper is reduced in the ground plane, DGS plays an important role in modern printed antennas to improve the parameters and enhance the performance.

\section{References}

[1] F. Yang, and Y. R. Samii, Electromagnetic band gap structures in antenna engineering, Cambridge University Press, 2008

[2] C. Caloz, H. Okabe, T. Iwai, and T. Itoh, "A Simple and Accurate Model for Microstrip Structures With Slotted Ground Plane," IEEE Microwave Wireless Components.Lett. vol. 14, no. 4, pp. 133-135, Apr. 2004.

[3] D. Ahn, J. S. Park, C. S. Kim, J. Kim, Y. Qian, and T. Itoh, "A design of the low-pass filter using the novel microstrip defected ground structure," IEEE Trans. Microwave Theory and Techniques, vol. 49, no. 1, pp. 86- 93, Jan. 2001.

[4] I. Chang, and B. Lee, "Design of DGS structures for harmonic control of active microstrip antenna," IEEE Antennas and Propagation Society International Symposium., vol. 2, pp. 852-855, 2002.

[5] N. C. Karmakar, S. M. Roy, and I. Balbin, "Quasi-Static modeling of defected ground structure," IEEE Trans. 


\section{International Journal of Science and Research (IJSR) \\ ISSN (Online): 2319-7064}

Index Copernicus Value (2013): 6.14 | Impact Factor (2014): 5.611

Microwave Theory Tech., vol. 54, no. 5, pp. 2160-2168, May. 2006.

[6] P. Bhartia, I. Bahl, R. Garg, and A. Ittipiboon, Microstrip Antenna Design Handbook, Artech House, Norwood, Mass,USA, 2000.

[7] RampalKushwaha, Prof. Kanchan Cecil, "Design and analysis of gain for rectangularmicrostrip patch antenna using symmetrical cuts", International Journal of AdvanceTechnology\& Engineering Research (IJATER), November 2011.

[8] John Q Howell, "Mirostrip antennas”, IEEE, Trans. Antenna and Propogation. Pp. 90-93, Jan 1975. 